Pak. j. sci. ind. res. Ser. B: biol. sci. 2019 62B(3) 178-182

\title{
Alternative Media Based on Papaya and Fish Extract for Glutathione Production in Saccharomyces cerevisiae
}

\author{
Nurul Dluha, Sri Widyarti and Widodo \\ Biology Department, Faculty of Mathematics and Natural Sciences, \\ Brawijaya University, Indonesia
}

(received April 27, 2017; revised September 24, 2017; accepted October 25, 2017)

\begin{abstract}
Glutathione (GSH) is an antioxidant that functions to protect cells from oxidative stress. It is used for medical purposes, as an additive in foods and cosmetics industry. The magnitude of these applications results in increased demand for glutathione every year, however, the cost of glutathione is high. The production of glutathione using an alternative source for the medium and the amino acids used in the media might be the solution for managing the high cost of glutathione production in yeast. This study uses an alternative media based on papaya and fish extract to reduce production costs. The fish extract contains glutamate, cysteine and glycine that can be utilised as a source of amino acid. This study suggested that media based on papaya extract could be employed to produce glutathione in yeast Saccharomyces cerevisiae. Moreover, administration of $5 \mathrm{mg} / \mathrm{mL}$ of fish extract could increase the glutathione production up to $36.36 \%$ as compared to a control. The optimum production of glutathione was obtained in a harvest time of $44 \mathrm{~h}$ culture. Therefore, further investigation by modifying the medium is warranted to produce glutathione in a cost friendly manner in the $S$. cerevisiae.
\end{abstract}

Keywords: glutathione, Saccharomyces cerevisiae, fish extract, papaya extract, yeast media

\section{Introduction}

Glutathione (GSH) is a thiol compound that is abundantly found in eukaryotes and can be used as an antioxidant to protect cells from oxidative stress (Dickinson and Forman, 2002; Penninckx, 2002). Moreover, glutathione also acts as an immune booster, a detoxifying agent for higher organisms, and a cell proliferation regulator (Pasternak et al., 2014; Pastore et al., 2003). Glutathione is not only used for medical purposes but also as an additive in foods and cosmetics industry ( $\mathrm{Li}$ et al., 2004). The magnitude of these benefits results in increased demand for glutathione every year. The supply of glutathione was not equal to its demand and this is thought to be due to the high cost of glutathione production. Glutathione production needs an optimum medium, addition of amino acids and high quantities of ATP. Glutathione production using an alternative source of medium, amino acids and organism might be the solution to manage the high cost of glutathione production.

Saccharomyces cerevisiae is often used to produce glutathione. According to Wen et al. (2005), this is because the yeast has the ability to accumulate glutathione efficiently for commercial production. The

*Author for correspondence; E-mail: widodo@ub.ac.id organism has been classified by the FDA as GRAS (generally regarded as safe) because of its presence as a human pathogen and because it is pyrogens free (Glick et al., 2010; Nevoigt, 2008). S. cerevisiae has ATP regeneration ability through the glycolytic pathway, so it does not require additional ATP (Li et al., 2004; Murata et al., 1981). However, it requires essential amino acids as a substrate for glutathione production in the fermentation process. The addition of these amino acids can increase the production cost. Therefore, as a solution to this issue, the amino acids were substituted by adding fish extract.

The fish extract contains several amino acids that are essential for glutathione production (Medikalink, 2012; Mustafa et al., 2012). Their concentrations were adjusted based on research by Wen et al. (2005). Thus, fish extract was selected to be used as a source of amino acids in glutathione production. The optimum medium also played a pivotal role in glutathione production and cell growth as stated by Zhang et al. (2007). In this study, an alternative source of nitrogen and carbon from meat broth extract and papaya extract was utilised to obtain cost friendly glutathione production in $S$. cerevisiae combined with the fish extract. 


\section{Materials and Methods}

Basic media selection for optimum yeast growth. Meat broth extract. Five hundred grams of beef was boiled in 2.5 litres of aquades for $1.5 \mathrm{~h}$. Following this step, the broth was filtered and poured into bottles. The extract was then autoclaved at $121^{\circ} \mathrm{C}$ for $20 \mathrm{~min}$ then freeze dried overnight.

Papaya extract. Two hundred grams of papaya were blended with 1 litre of aquades. The extract was then filtered and poured into bottles. The extract was freeze dried overnight.

Fish extract. A stock of fish extract (No. Cat P140116A02 \& P150415A09: VipAlbumin $®)$ was made by dissolving 12 capsules $(500 \mathrm{mg}$ ) into $120 \mathrm{~mL}$ of sterile distilled water and the mixture was homogenised. The solution was then centrifuged at $4000 \mathrm{rpm}$ for one hour. The supernatant was collected and centrifuged again for $10 \mathrm{~min}$. The resulting supernatant was filtered through a $0.45 \mu \mathrm{m}$ filter and stored at $20^{\circ} \mathrm{C}$.

S. cerevisiae W303-1b was obtained from the Department of Microbiology, Kässel University, Germany. The culture was grown in $40 \mathrm{~mL}$ culture medium that contained three types of papaya extract concentration. The first media contained yeast extract $1 \%(\mathrm{w} / \mathrm{v})$ $\left(\right.$ Bacto $\left.^{\mathrm{TM}}\right)$, meat broth extract $0.04 \%(\mathrm{w} / \mathrm{v})$, and papaya extracts $0.13 \%(\mathrm{w} / \mathrm{v})$. The second media contained yeast extract $1 \%(\mathrm{w} / \mathrm{v})$, broth extract $0.04 \%(\mathrm{w} / \mathrm{v})$, and papaya extracts $0.26 \%(\mathrm{w} / \mathrm{v})$, and the third media contained yeast extract $1 \%(\mathrm{w} / \mathrm{v})$, broth extract $0.04 \%(\mathrm{w} / \mathrm{v})$, and papaya extracts $0.39 \%(\mathrm{w} / \mathrm{v})$. The $\mathrm{pH}$ of each medium was 6.5. The yeast was cultured at $30{ }^{\circ} \mathrm{C}, 200 \mathrm{rpm}$ for $48 \mathrm{~h}$. Cell concentration was measured using spectrophotometer at the absorbance OD600 every $2 \mathrm{~h}$ for $24 \mathrm{~h}$ then every $3 \mathrm{~h}$ up to $36 \mathrm{~h}$ and every $4 \mathrm{~h}$ until $48 \mathrm{~h}$. The absorbance result was then used to establish the growth curve and to determine the optimum media for yeast growth. The most beneficial media was then used to produce glutathione by fish extract induction.

Glutathione production in yeast by inducing fish extract. Glutathione production in yeast was carried out in the basic medium from the previous selection. The culture was prepared in a $75 \mathrm{~mL}$ flask containing $25 \mathrm{~mL}$ of the basic medium, then a further $10 \%$ of medium with seed culture was added $(\mathrm{OD} 600=0.6)$. The yeast culture was incubated at $30^{\circ} \mathrm{C}, 200 \mathrm{rpm}$ for $24 \mathrm{~h}$. After $24 \mathrm{~h}$, the culture was enriched with fish extract at concentrations of $0,5,10$ and $15 \mathrm{mg} / \mathrm{mL}$
(VipAlbumin $\left.{ }^{\circledR}\right)$, according to Wen et al. (2005). Fish extract from Ophiocephalus striatus contains essential amino acids. $100 \mathrm{~g}$ fish albumin contains $15 \mathrm{~g}$ of glutamic acid, $1.11 \mathrm{~g}$ of glycine and $1.07 \mathrm{~g}$ of cysteine as indicated by Medicalink (2012). The process of yeast culture was then continued by incubating at $30^{\circ} \mathrm{C}, 200 \mathrm{rpm}$ for $44 \mathrm{~h}$ as stated by Liang et al. (2008).

Glutathione measurement. The yeast culture was harvested at $36 \mathrm{~h}$ and $44 \mathrm{~h}$ after inoculation. The culture broth was centrifuged at $4000 \mathrm{rpm}$ for $10 \mathrm{~min}$. The cells were then washed twice with sterile distilled water. Cells were extracted with $40 \%(\mathrm{v} / \mathrm{v})$ ethanol at $30{ }^{\circ} \mathrm{C}$ for $2 \mathrm{~h}$ and centrifuged at $4000 \mathrm{rpm}$ for $10 \mathrm{~min}$. The supernatant was used for the GSH assay using the DTNB method (GBioscience, 2012; Xiong et al., 2009; Wei et al., 2003).

Statistical analysis. Data were statistically analysed using one-way ANOVA (P value $\leq 0.05$ ) and continued with Duncan test. All statistical analyses were performed using SPSS version 16.0 for Windows.

\section{Results and Discussion}

Basic media selection was conducted to obtain the best concentration of papaya extract within which to grow the yeast. The data suggested that the three variations of papaya extract could be used as growth media for yeast. Therefore, the media could be used to substitute the standard media of yeast that consists of yeast extract. Based on research by Gross and Acosta (1991), papaya contains galactose that can be a source of carbon, and it can therefore be used as a carbon source. Media number 2 and 3 showed similar patterns in the growth curve (Fig. 1) that warrants their use as media to produce glutathione. Of the two, media number 2 was selected for use in glutathione production since the medium contained a lower concentration of papaya $(0.26 \%(\mathrm{w} / \mathrm{v}))$.

Further study to produce glutathione was carried out using media number 2 and induced by fish extract at different concentrations $(0,5,10$ and $15 \mathrm{mg} / \mathrm{mL})$. The induction of glutathione production by fish extract was carried out after $24 \mathrm{~h}$ of culture or in phase III. Wen et al. (2005) stated that there are three phases in the process of glutathione production by $S$. cerevisiae i.e. Phase I (0-8 h), Phase II (8-14 h) and phase III (18-24 h). Phase III is the stationary phase in which cell growth stops, but during which glutathione production begins to increase significantly. Research conducted by Liang 
et al. (2008) demonstrated that the best time to add fish extract is at the late $\log$ and early stationary phase because it can avoid inhibition of cell growth while also increasing the production of glutathione. Fish extract serves as a source of essential amino acids in the production of glutathione because it contains cysteine, glutamic acid, and glycine as shown by Medikalink (2012). Those amino acids are essential amino acids in the production of glutathione according to Wen et al. (2005). Besides that, the fish extract also contained serine, which is an amino acid that can form cysteine. Therefore, the addition of serine can also increase glutathione production (Suzuki et al., 2011; Wen et al., 2004).

This study demonstrated that fish extract at a concentration of $5 \mathrm{mg} / \mathrm{mL}$ was capable of increasing glutathione production while the addition of extract at concentrations of $10 \mathrm{mg} / \mathrm{mL}$ and $15 \mathrm{mg} / \mathrm{mL}$ did not show any significant difference (Fig. 2). The increasing yield of glutathione in medium induced by $5 \mathrm{mg} / \mathrm{mL}$ of fish extract reached a level that was $36.36 \%$ higher than the control. Wen et al. (2005) used $10 \mathrm{mM}$ glutamate which is equivalent to the glutamate content in $10 \mathrm{mg} / \mathrm{mL}$ fish extract. However, the concentration of fish extract that increased glutathione production was $5 \mathrm{mg} / \mathrm{mL}$ which in turn

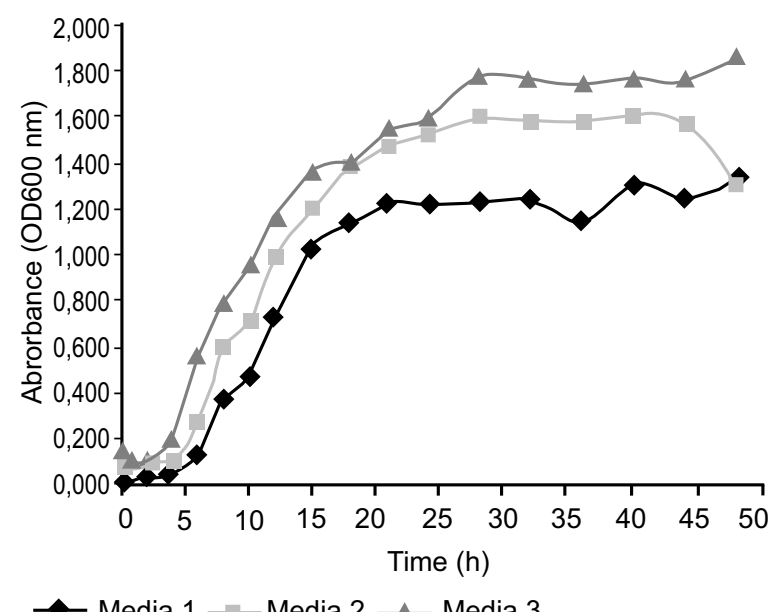

Fig. 1. Growth curve of $S$. cerevisiae W303-1B using media containing yeast extract $1 \%$ $(\mathrm{w} / \mathrm{v})\left(\right.$ Bacto $\left.^{\mathrm{TM}}\right)$, broth extract $0.04 \%(\mathrm{w} / \mathrm{v})$ and supplemented by three different quantities of papaya extract, $0.13 \%(\mathrm{w} / \mathrm{v})$ (Media 1), 0.26\% (w/v) (Media 2) and $0.39 \%(\mathrm{w} / \mathrm{v})$ (Media 3). means that the glutamate content in $5 \mathrm{mg} / \mathrm{mL}$ of fish extract can be assumed to be equivalent to $5 \mathrm{mM}$ glutamate. This data corresponds to data from Tang et al. (2015) where the addition of $5 \mathrm{mM}$ glutamate, $5 \mathrm{mM}$ glycine, and $5 \mathrm{mM}$ cysteine to the culture medium can increase glutathione production. Tang et al. (2015) used the same strain of $S$. cerevisiae i.e. W303-1b. Based on the statistical analysis results, these demonstrated that there was no significant difference in harvest time, but there was the tendency to increase GSH to $44 \mathrm{~h}$ compared to $36 \mathrm{~h}$ after inoculation (Fig. 2). This indicates that the GSH optimum harvest time is $44 \mathrm{~h}$ which is the end of the stationary phase. This is because in the stationary phase, the cell number has reached the maximum number of cells that can grow, and reduced the nutritional content of the culture medium. This reduction in the nutritional content places $S$. cerevisiae under stressful conditions that can trigger the production of glutathione according to Wen et al. (2005).

Previous research on the optimisation of media for glutathione production used a high quantity of supplements. In this study, however, only a simple medium was used as listed in Table 1. This medium still resulted in the production of glutathione although the yield was low. The results suggested that the use of media based

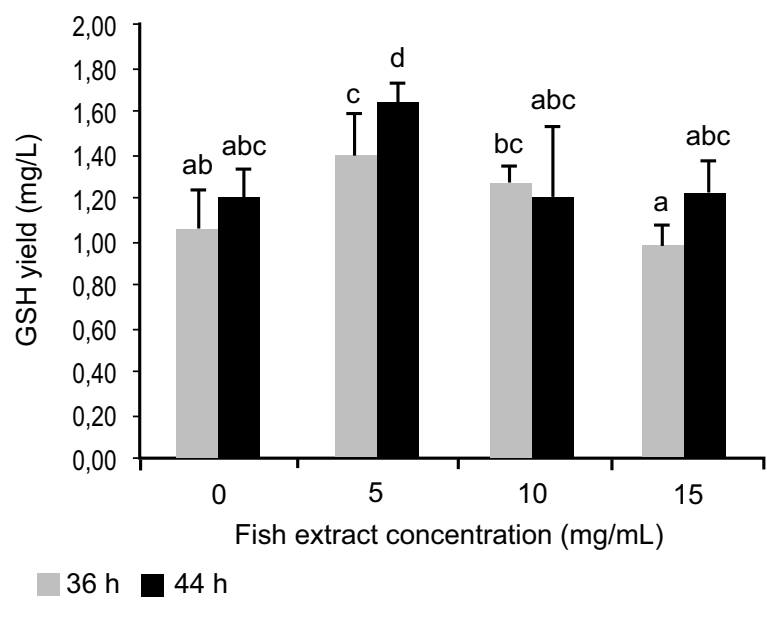

Fig. 2. The GSH yield using the papaya extract media supplemented with fish extract. Administration of $5 \mathrm{mg} / \mathrm{mL}$ fish extract could increase the production of GSH, with the highest concentration of GSH being harvested in culture after $44 \mathrm{~h}$. The histogram presents the mean \pm SD of the GSH concentration and the analysis of variance was conducted at $P$-value $\leq 0.05$. 
Table 1. Comparison of media used and the GSH yield

\begin{tabular}{|c|c|c|c|}
\hline Media used & GSH yield & S. cerevisiae & References \\
\hline $\begin{array}{l}70 \mathrm{~g} / \mathrm{L} \text { glucose, } 3 \mathrm{~g} / \mathrm{L} \text { yeast extract, } 5 \mathrm{~g} / \mathrm{L} \text { peptone, } \\
70 \mathrm{~g} / \mathrm{L} \text { malt extract, } 20 \mathrm{~g} / \mathrm{L} \text { molasses, } 5.6 \mathrm{~g} / \mathrm{L} \mathrm{MgSO}_{4} \text {, } \\
16 \mathrm{mg} / \mathrm{L} \mathrm{ZnSO}_{4}, 7 \mathrm{~g} / \mathrm{L}\left(\mathrm{NH}_{4}\right)_{2} \mathrm{HPO}_{4} \text { and } 0.2 \mathrm{mg} / \mathrm{L} \text { thiamine }\end{array}$ & $74.6 \pm 0.00 \mathrm{mg} / \mathrm{L}$ & S. cerevisiae $\mathrm{T} 65$ & Zhang et al. (2007) \\
\hline $10 \mathrm{~g} / \mathrm{L}$ yeast extract, $20 \mathrm{~g} / \mathrm{L}$ tryptone and $20 \mathrm{~g} / \mathrm{L}$ glucose & $\begin{array}{l}98.7 \pm 7.30 \mathrm{mg} / \mathrm{L} \\
\mathrm{W} \mathrm{303-1b}\end{array}$ & S. cerevisiae & Tang et al. (2015) \\
\hline $\begin{array}{l}\text { Yeast extract } 1 \%(\mathrm{w} / \mathrm{v}) \text {, broth extract } 0.04 \%(\mathrm{w} / \mathrm{v}) \text {, } \\
\text { and papaya extracts } 0.26 \%(\mathrm{w} / \mathrm{v})\end{array}$ & $\begin{array}{l}1.65 \pm 0.08 \mathrm{mg} / \mathrm{L} \\
\mathrm{W} 303-1 \mathrm{~b}\end{array}$ & S. cerevisiae & Present study \\
\hline
\end{tabular}

on papaya extract supplemented with fish extract could be used for the production of glutathione. The media requires further investigation to ensure the production of glutathione in a cost manner in $S$. Cerevisiae.

\section{Conclusion}

This study indicated that media based on papaya extract could be used to produce glutathione in yeast. The supplementation of this medium with $5 \mathrm{mg} / \mathrm{mL}$ of fish extract could increase glutathione production up to $36.36 \%$ in quantity as compared to the control. Therefore, further investigation by modifying the medium is warranted to produce glutathione in a cost friendly manner in $S$. cerevisiae.

\section{Acknowledgement}

The authors would like to thank Prof. Raffael Schaffrath and Prof. Wolfgang Nellen for providing S. cerevisiae W303-1b for this research.

Conflict of Interest. The authors declare no conflict of interest.

\section{References}

Dickinson, D.A., Forman, H.J. 2002. Cellular glutathione and thiols metabolism. Biochemical Pharmacology, 64: 1019-1026.

GBioscience, 2012. Ellman's Reagent. Available at: Www.gbioscience.com.

Glick, B.R., Pasternak, J.J., Patten, P.C.L. 2010. Molecular Biotechnology Principles and Applications of Recombinant DNA. $4^{\text {th }}$ editions, ASM Press, Washington, USA.

Gross, K.C., Acosta, P.B. 1991. Fruits and Vegetables are a source of galactose: Implications in Planning the Diets of Patients with Galactosaemia. Journal of Inherited Metabolic Disease, 14: 253-258.

Li, Y., Wei, G., Chen, J. 2004. Glutathione: a review on biotechnological production. Applied Microbiology and Biotechnology, 66: 233-242.

Liang, G., Liao, X., Du, G., Chen, J. 2008. Optimization of amino acids addition for efficient production of glutathione in Candida utilis. Biochemical Engineering Journal, 41: 234-240.

Murata, K., Tani, K., Kato, J., Chibata, I. 1981. Glycolytic pathway as an ATP generation system and its application to the production of glutathione and NADP. Enzyme and Microbial Technology, 3: 233-242.

Mustafa, A., Widodo, M.A., Kristianto, Y. 2012. Albumin and zinc content of snakehead fish (Channa striata) extract and its role in health. IEESE International Journal of Science and Technology, 1: 1-8.

Nevoigt, E. 2008. Progress in metabolic engineering of Saccharomyces cerevisiae. Microbiology and Molecular Biology Reviews: MMBR, 72: 379-412.

Pasternak, T., Asard, H., Potters, G., Jansen, M.A. 2014. The thiol compounds glutathione and homoglutathione differentially affect cell development in alfalfa (Medicago sativa L.). Plant Physiology et Biochemistry, 74: 16-23.

Pastore, A., Federici, G., Bertini, E., Piemonate, F. 2003. Analysis of glutathione: Implication in redox and detoxification. Clinica Chimica Acta, 333: 19-39.

Penninckx, M.J. 2002. An overview on glutathione in Saccharomyces versus non-conventional yeasts. FEMS Yeast Research, 2: 295-305.

Suzuki, T., Yokoyama, A., Tsuji, T., Ikeshima, E., Nakashima, K., Ikushima, S., Kobayashi, C., Yashida, S. 2011. Identification and characterization of genes involved in glutathione production in yeast. Journal of Bioscience and Bioengineering, 112: $107-113$.

Tang, L., Wang, W., Zhou, W., Cheng, K., Yang, Y., 
Liu, M., Cheng, K., Wang, W. 2015. Three-pathway combination for glutathione biosynthesis in Saccharomyces cerevisiae. Microbial Cell Factories, 14: 139.

Wei, G., Li, Y., Du, G., Chen, J. 2003. Effect of surfactants on extracellular accumulation of glutathione by Saccharomyces cerevisiae. Process Biotechnology, 38: 1133-1138.

Wen, S.H., Zhang, T., Tan, T.W. 2005. Optimization of the amino acid composition in glutathione fermentation. Process Biochemistry, 40: 3474-3479.

Wen, S.H., Zhang, T., Tan, T.W. 2004. Utilization of amino acids to enhance glutathione production in Saccharomyces cerevisiae. Enzyme and Microbial Technology, 35: 501-507.

Xiong, Z.Q., Guo, M.J., Guo, Y.X., Chu, J., Zhuang, Y.P., Zhang, S.L. 2009. Efficient extraction of intracellular reduced glutathione from fermentation broth of Saccharomyces cerevisiae by ethanol. Bioresource Technology, 100: 1011-1014.

Zhang, T., Wen, S., Tan, T. 2007. Optimization of the medium for glutathione production in Saccharomyces cerevisiae. Process Biochemistry, 42: 454458. 